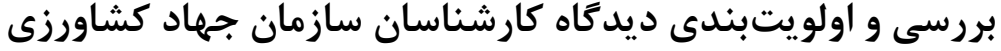

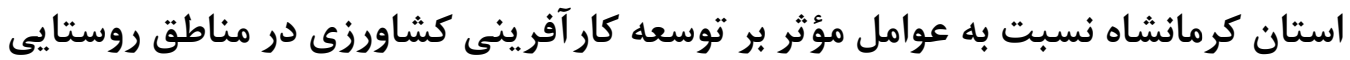

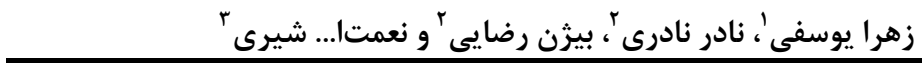

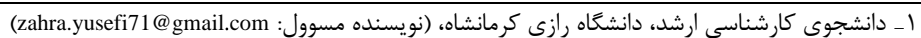

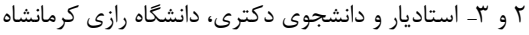 \\ تاريخ دريافت:
}

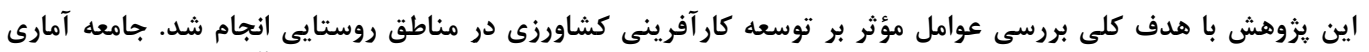

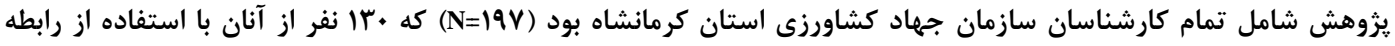

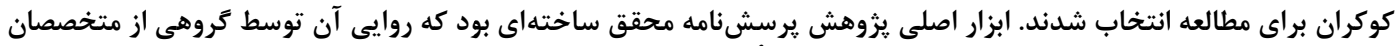

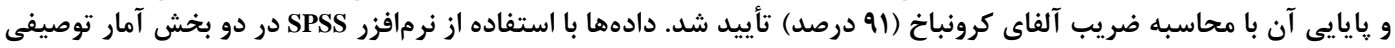

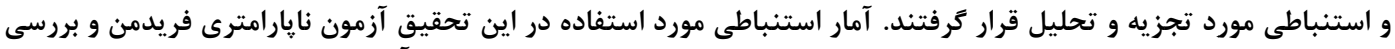

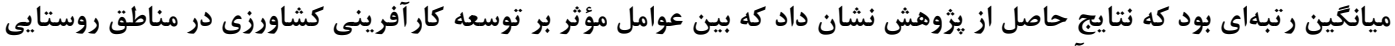

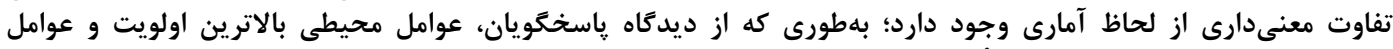

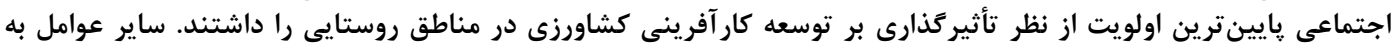

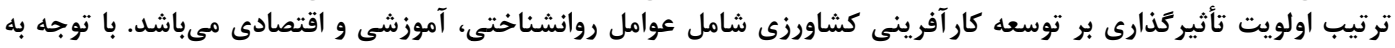

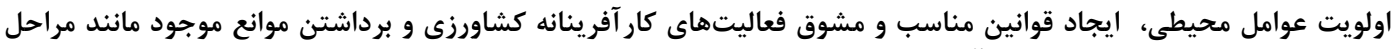

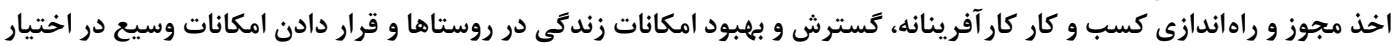

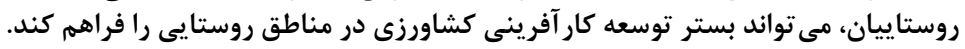

وازههاى كليدى: توسعه روستايى، كار آفرينى كشاورزى، سازمان جهاد كشاورزى استان كرمانشاه

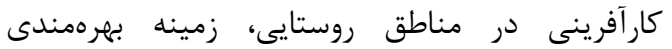

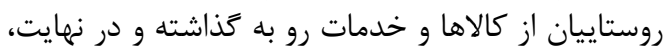

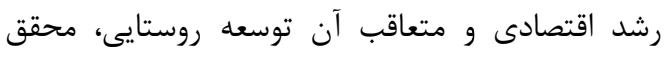
مىشود (9). رشد جمعيت و كاهش من منابع موجود نه نه تنها

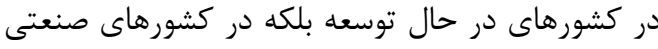

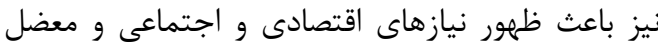

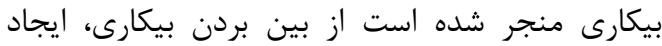

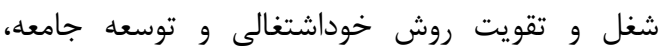
ضرورت كارآفرينى را افزايش دادهاند (سT)

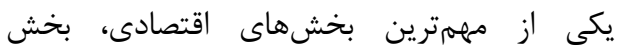

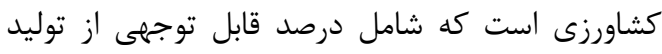

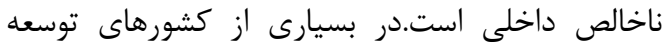

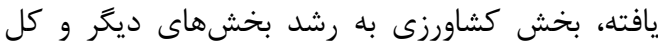

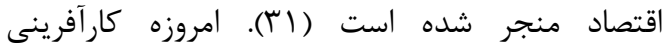

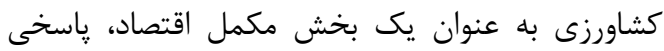

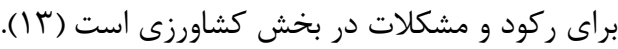

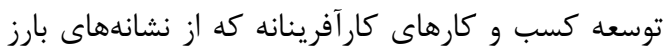

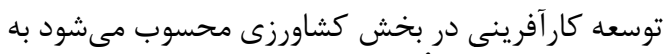

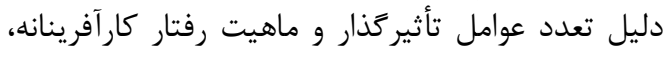

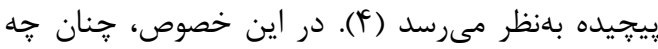

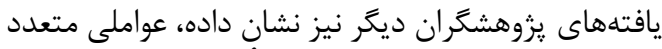

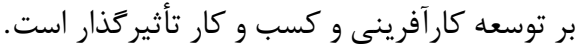

مطابق آمار منتشر شده از طرف سازمان ملل تقريباً

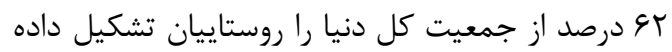

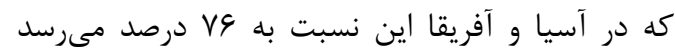

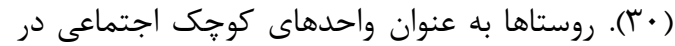

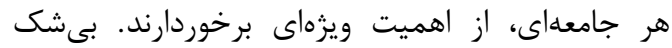

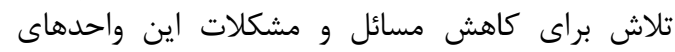

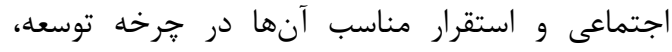

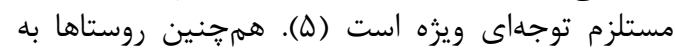

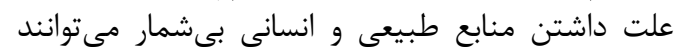

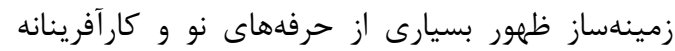

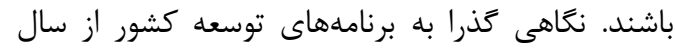

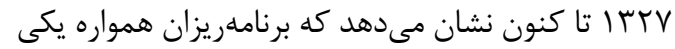

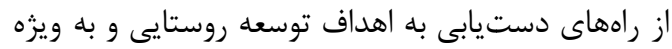

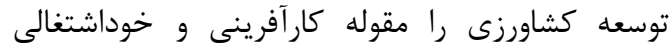

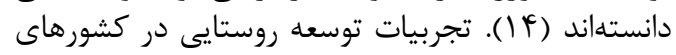

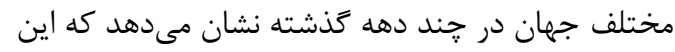

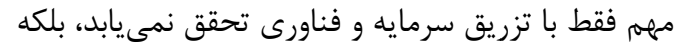

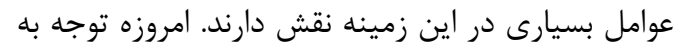

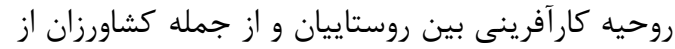

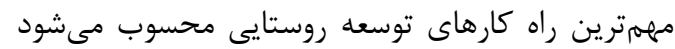

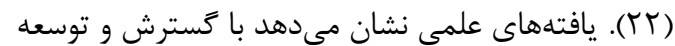


اين مطالعه، سهم و نقش عوامل ذيل در توسعه كسب و و كورئ

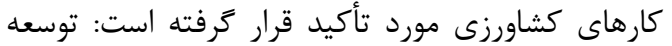

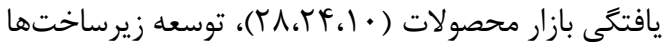

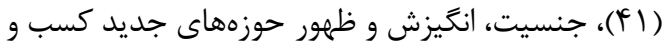

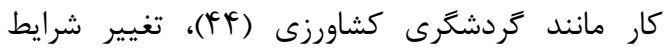

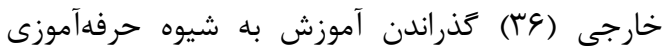

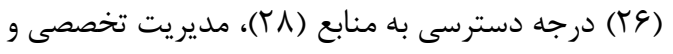

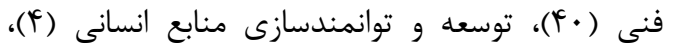

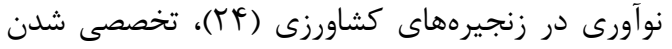

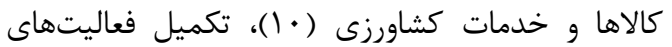

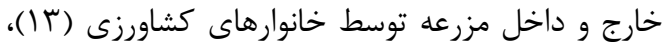

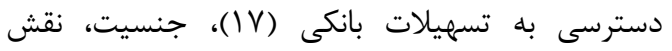

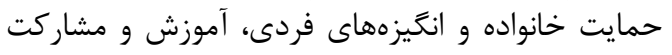

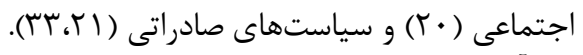

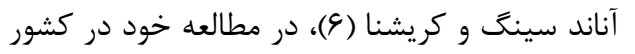

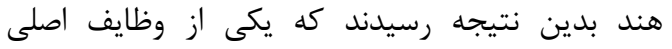

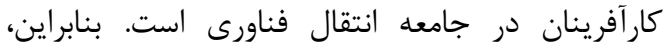

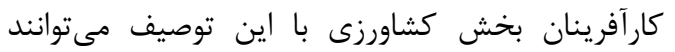

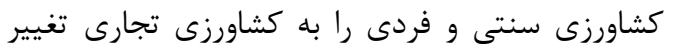

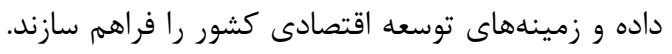

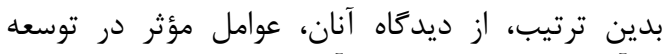

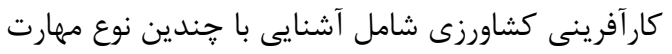

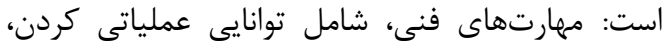

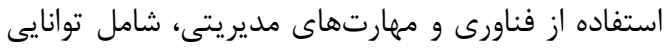

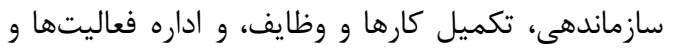

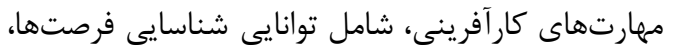

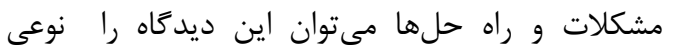

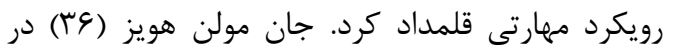

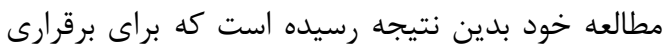

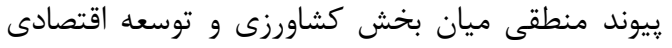

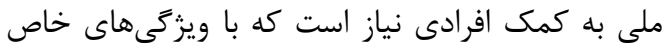

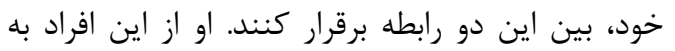

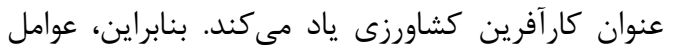

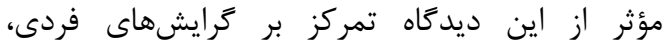

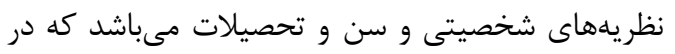

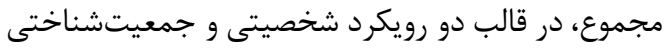

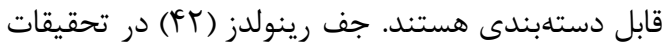

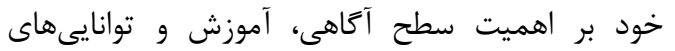

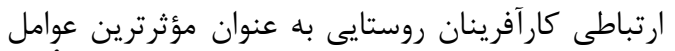

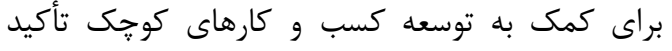

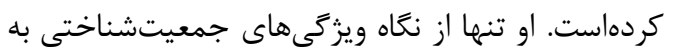

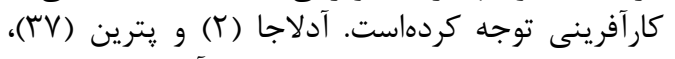

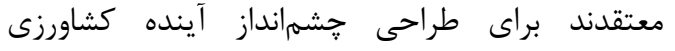

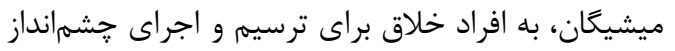
در سطوح مختلف (ملى، منطقهاى و محلى بلى برنامهاريزى

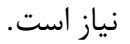

بخش كشاورزى، بلويزه در كشورهاى در حال توسعه،

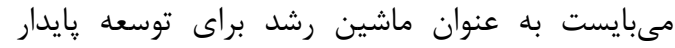

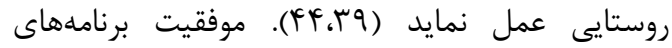

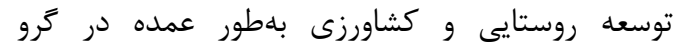

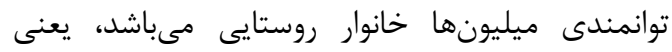

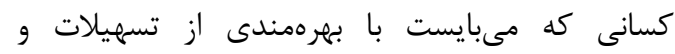

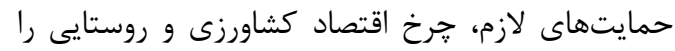

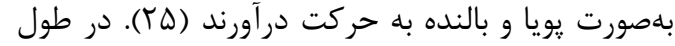
دهه كذشته در ارويا، توسعه كارآفرينى كشاورزى يك آريد

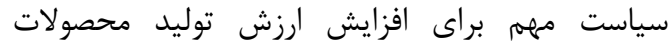

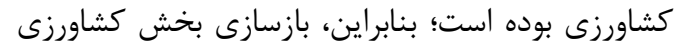

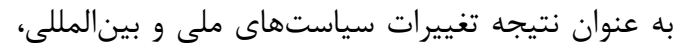

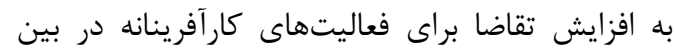

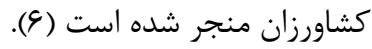

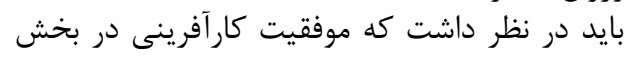

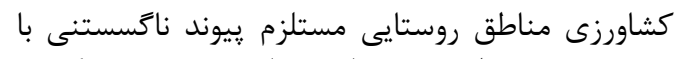

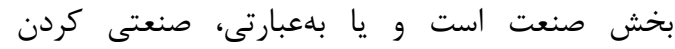

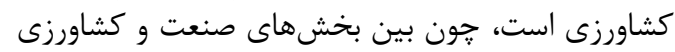

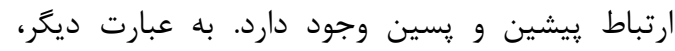

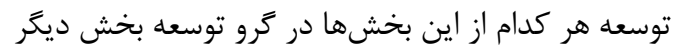

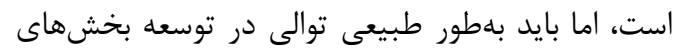

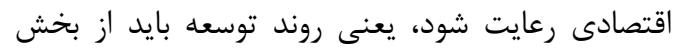

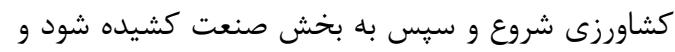

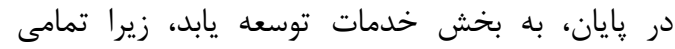

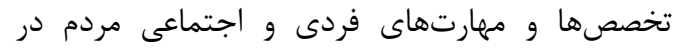

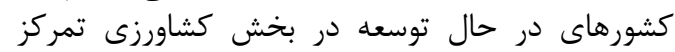

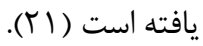
بدين ترتيب، كارآفرينى در محيط روستائى دافي داراى

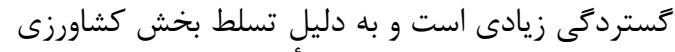

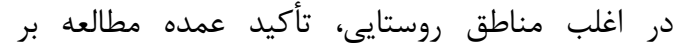

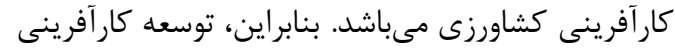

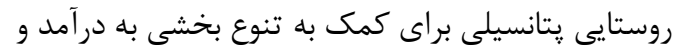

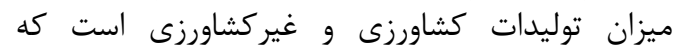

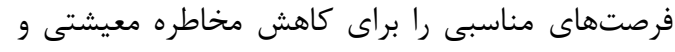

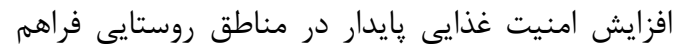

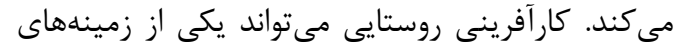

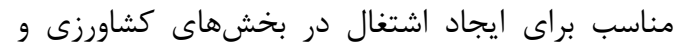

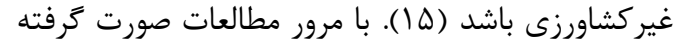

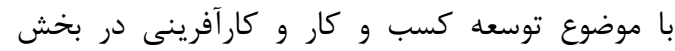

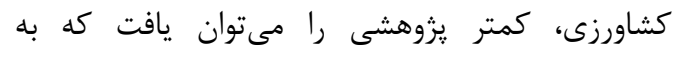

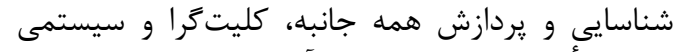

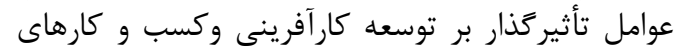

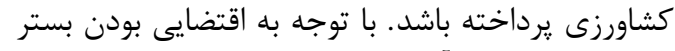

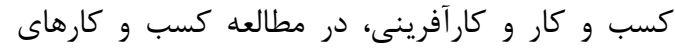

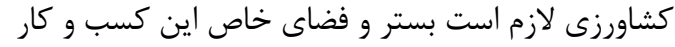

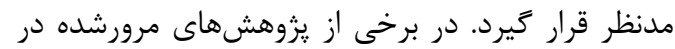




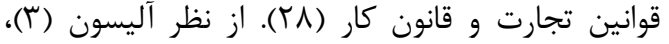

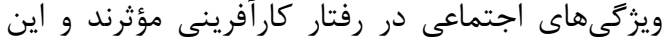

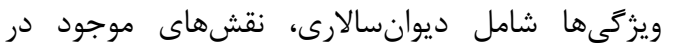

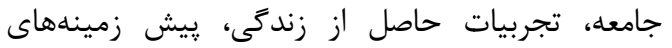

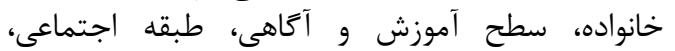

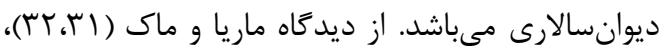

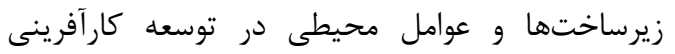

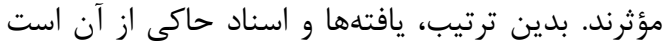

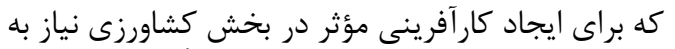

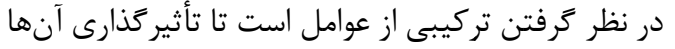

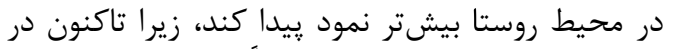

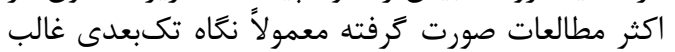

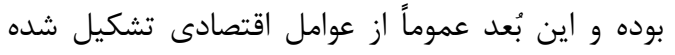

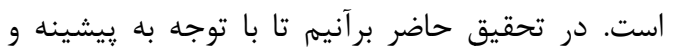

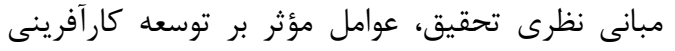

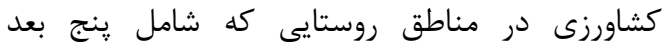

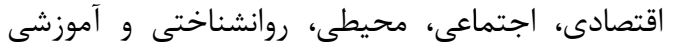

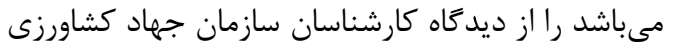

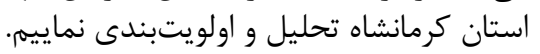

يكى از خالشهاى بخش كشاورزى در حوزه عوامل

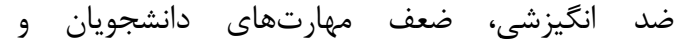
دانشآموختكان كشاورزى در زمينه توسعه كارآنرينى

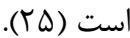

نمونه ديكر متعلق به كاروليناى شمالى در آمريكاست

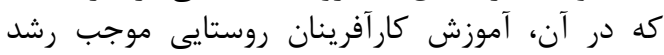

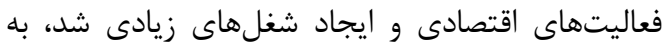

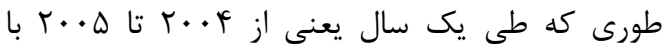

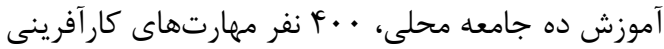

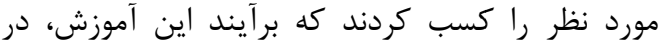

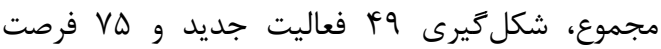

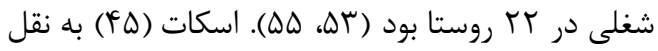

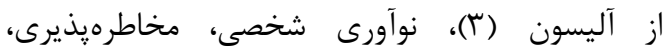

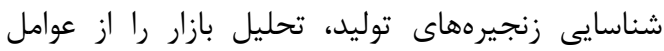

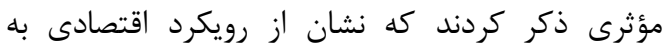

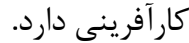
از موانع قانونى كه محدوديتهايى رار را در زمينه

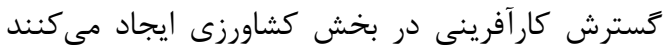

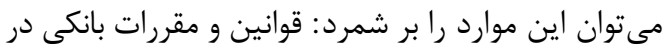

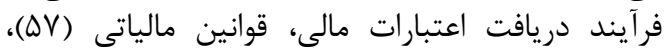

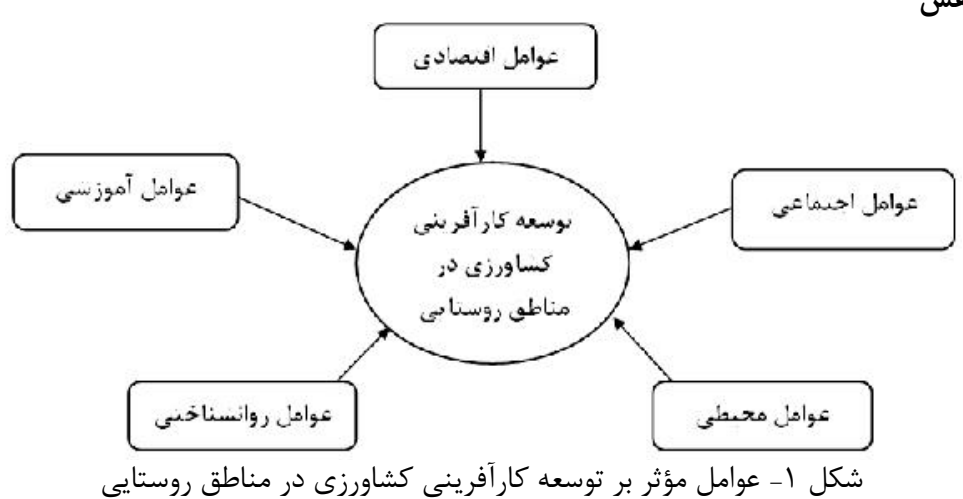

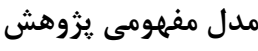

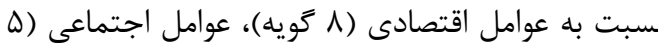

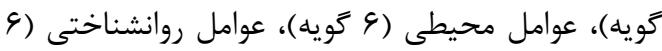

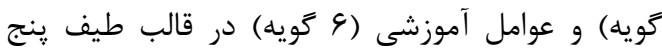

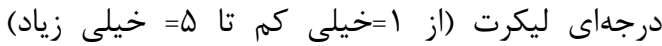

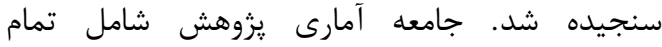

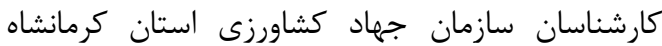

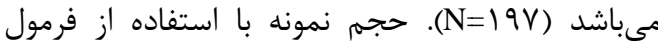

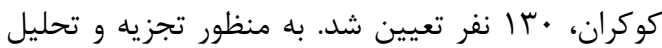

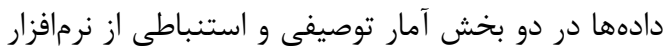
SPSS

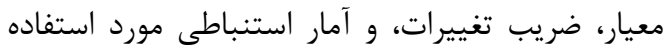

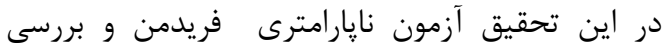

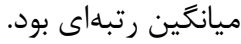

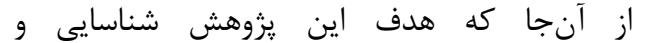

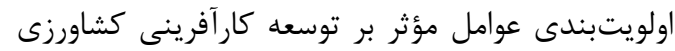

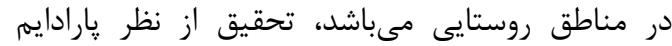

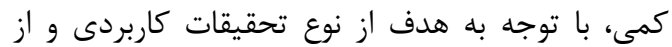

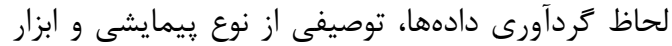

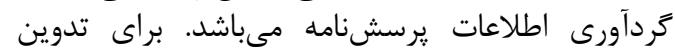

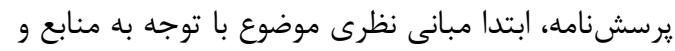

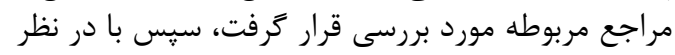

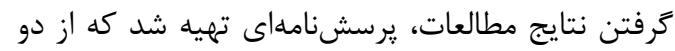

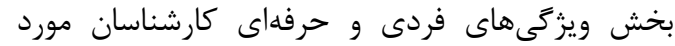

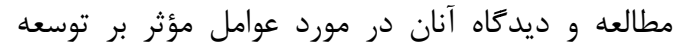

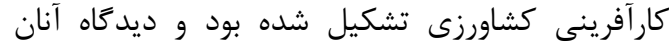


روانشناختى، آموزشى، از آزمون ميانكَين استفاده شد.

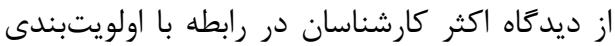

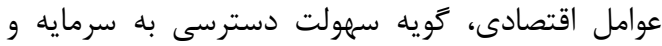

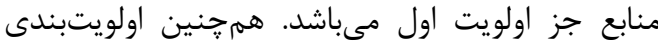

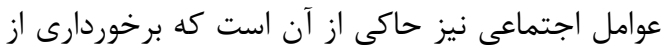

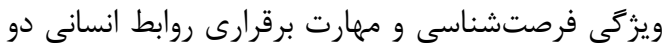

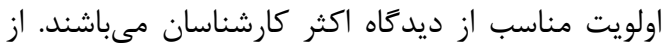

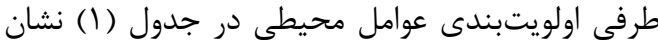

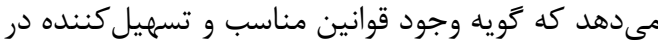

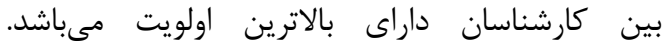

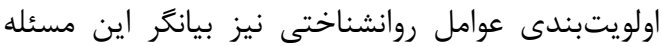
است كه كويه تحمل شكست كشاورزان و واراده بران براي

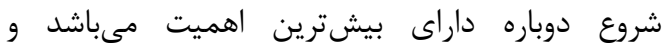

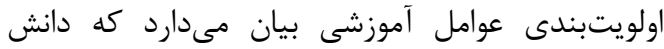

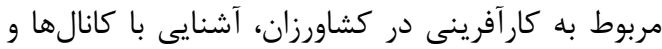

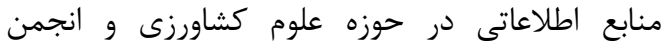
كارآفرينى كشاورزى در مناطق روزيع روستايى جزو بالاترين اولويتها مئباشند.
نتايج و بحث الف- ويزگكى هاى فردى كارشناسان جهاد كشاورزى

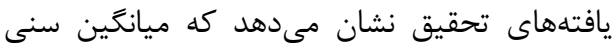

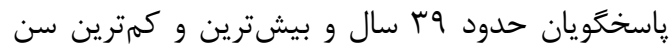

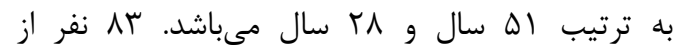
كارشناسان مورد مطالعه مرد (

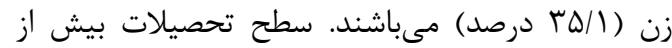

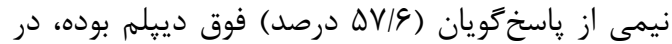

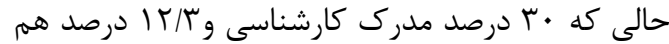

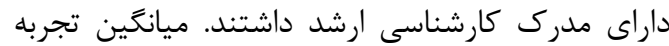
كارى كارشناسان جهاد كشاورزى استان كرمانشان الشاه حدان حدود

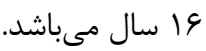

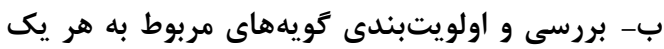

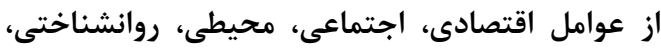
آموزشى مؤثر بر توسعه كار آفرينى كشاورزى مريطى در مناطق

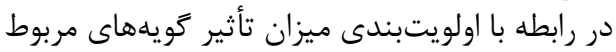
روستايى به هر يك از عوامل اقتصادى، اجتماعى، محيطى،

\begin{tabular}{|c|c|c|c|c|c|}
\hline ضريب تغييرات & مانحراف & ميانكَين & 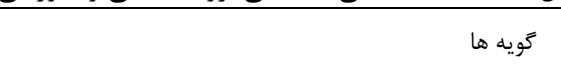 & اولويت & عوامل \\
\hline$\cdot / T \cdot \Lambda$ &.$/ v$ & $F / 1 \wedge$ & سهيولت دسترسى به سرمايه و منابع & 1 & \\
\hline.$/ r \cdot 9$ &.$/ 11$ & $4 / . q$ & اصلاح نظام قيمت كذارى در بخش كشاورزى & r & \\
\hline . TIs &.$/ 9 \mathrm{~V}$ & r/ar & افزايش حمايتهاى قيمتى و اختصاص يارانه به كشاورزان & r & \\
\hline.$/ r T \Delta$ &.$/ v \Delta$ & r/Ar & 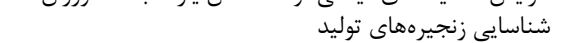 & r & \\
\hline . &.$/ A F$ & r/Ar & كاهش حاشيه سود فعاليتهاى غير مولد & $\Delta$ & اقتصادى \\
\hline$. / r+9$ &.$/ v \Delta$ & $r / v$. & توانايى بازاريابي محصولات كشاورزى & \& & \\
\hline.$/ 49 \Delta$ &.$/ \wedge 9$ & $r / q 4$ & اعطاى تخفيفهاى مالياتى & $\mathrm{r}$ & \\
\hline rir & . /qr & $r / \uparrow \Lambda$ & 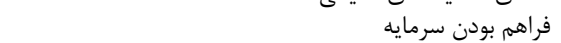 & $\wedge$ & \\
\hline.$/$ TrQ & . /Ar & $r / 9 \Lambda$ & برخوردارى از خصوصيت "فرصتشناسى" & 1 & \\
\hline$. / r \Delta \mid$ & rar & $r / 91$ & ميهارت برقرارى روابط انسانى مي & r & \\
\hline.$/$ / 99 & $. / 1 \mid$ & $r / 9$. & توانايي به حداقل رساندن مخاطرات & r & اجتماعي \\
\hline rir &.$/ 19$ & $r / \Delta T$ & قدرت "توانايى تصميم كيرى" & r & \\
\hline . &.$/ \mathrm{NA}$ & 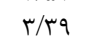 & تمايل به ارائه عقايد خود به ديخران & a & \\
\hline.$/ 4 \cdot 9$ & $\cdot / \mathrm{Vr}$ & $f / T)$ & وجود قوانين مناسب و تسهيل كننده & 1 & \\
\hline זr/ &.$/ 99$ & $r / \Lambda \Delta$ & دستر سى به منابع اطلاعاتى و دانش همَانى & r & \\
\hline.$/ F 4 F$ &.$/ v^{4}$ & $r / V r$ & كسترش امكانات زندى در روستا & r & \\
\hline.$/$ rar &.$/ \mathrm{Vr}$ & $r / \Delta V$ & توسعه امكانات حمل و نقل در روستا & f & بطى \\
\hline.$/ T \Delta F$ &.$/ 19$ & $r / T F$ & 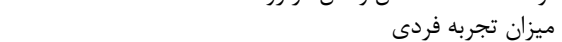 & $\Delta$ & \\
\hline. &.$/ 9$. & $r / N$ & ي يش زمينه هاى خانواده & 4 & \\
\hline.$/ 49$ & .199 & $r / r f$ & تحمل شكست كشاورزان و اراده براى شروع دوباره & 1 & \\
\hline . &.$/ \mathrm{q}$ & $r / \pi r$ & درجه و ميزان ريسك يذيرى & r & \\
\hline זr &.$/ 1$. & $r / .9$ & مثبت انديشى كشاورزان و قطعيت در كار & r & \\
\hline r &.$/ 19$ & T/AF & اعتماد به نفسي كشاوززان & r & روانشناختى \\
\hline צ &.$/ 9$. & $r / 9 T$ & نياز به موفقيت و كسب توفيق از جانب كشاورزان & a & \\
\hline גז//. &.$/ 9$. & $r / 4 Q$ & ابتكار و خلاقيت كشاورزان & q & \\
\hline.$/ T H T$ &.$/ \mathrm{NI}$ & $r / v \cdot$ & دانش مربوط به كارآفرينى در كشاورزان & 1 & \\
\hline . MFF & .199 & $r / q \mu$ & آشنايى با كانال ها و منابع اطلاعاتى در حوزه علوم كشاورزى & r & \\
\hline$. / \pi+v$ &.$/ \mathrm{V} 9$ & $r / \uparrow \Lambda$ & انجمن كارآفرينى كشاورزى در مناطق روستايى & r & \\
\hline.$/ T V F$ &.$/ \mathrm{N}$ & $r / r$. & تناسب داشتن آموزش مروجين با تجربه فعاليتهاي كشاورىى & r & 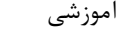 \\
\hline.$/$ rVq &.$/ \Lambda \Delta$ & r/Tr & برقرارى ارتباط بين بخش كشاوزى با دانشًاهها & $\Delta$ & \\
\hline.$/ \Gamma \Lambda$ &.$/ \mathrm{A}$ & $r / / \gamma$ & بركزارى دورههاى آموزشى مهارتى به كشاورزان & 9 & \\
\hline
\end{tabular}


كار

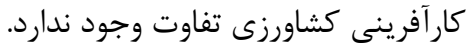

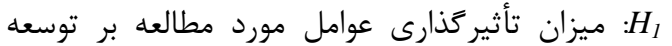
كارآفرينى كشاورزى متفاوت است

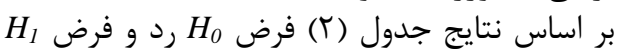

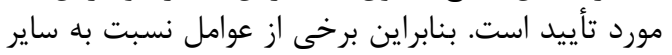

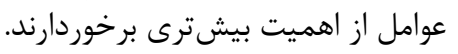

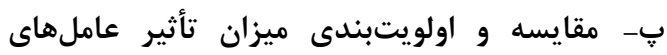

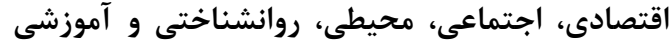

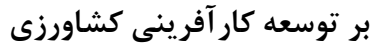

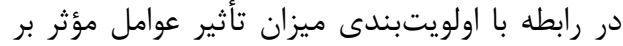

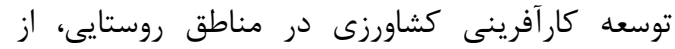

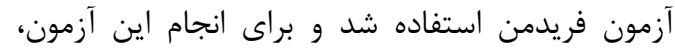

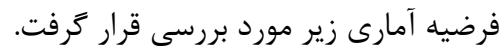

\begin{tabular}{|c|c|c|c|}
\hline & ي كريدمن & حاصل از & جدول r- دادههاى | \\
\hline سطح معنى دارى & درجه آزادى & Chi-square & نتيجه آزمون \\
\hline$\cdot / \ldots$ & $r$ & 19 & فرض صفر رد مىشود \\
\hline
\end{tabular}

پِاسخكويان، عوامل محيطى، روانشناختى، آموزشى،

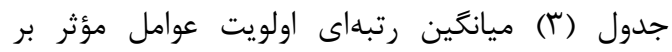
اقتصادى و اجتماعى بهترتيب در اولويت قرار دارند.

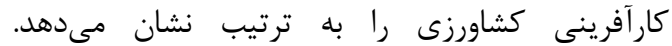

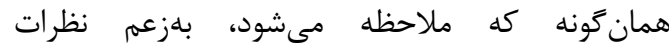

\begin{tabular}{|c|c|c|}
\hline ميانگين رتبهاى & عوامل مؤثر بر توسعه كارآفرينى كشاورزى & رتبه \\
\hline$r / 41$ & عوامل محيطى & 1 \\
\hline$r / \tau \wedge$ & 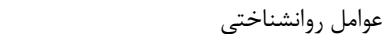 & r \\
\hline$r / l \varphi$ & عوامل آموزشى & r \\
\hline$r / 9$ & عوامل اقتصادى & f \\
\hline$r / .9$ & عوامل اجتماعى & $\Delta$ \\
\hline
\end{tabular}

طبق اولويتبندى نظرات ياسخدهندكان بيشترين

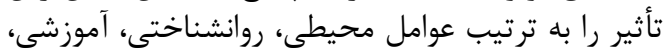

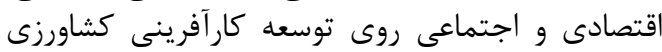

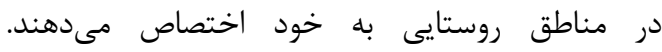

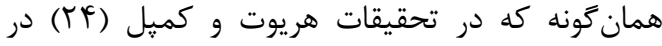

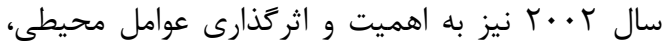

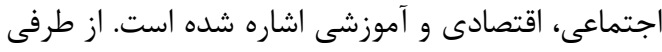

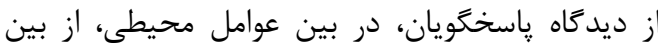

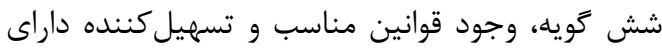

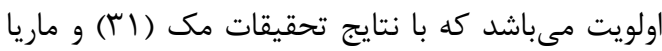

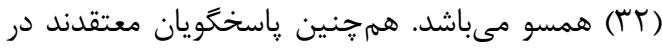

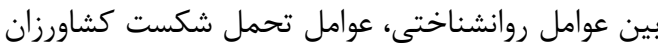

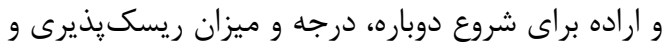

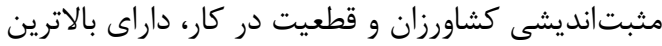

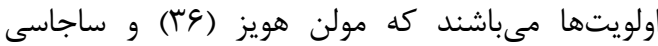

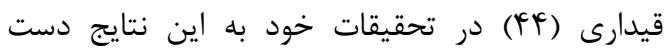

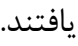
همرجنين بر اساس نظرات كارشناسان ياسخدهنده،

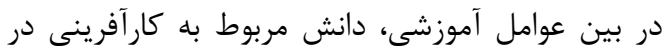

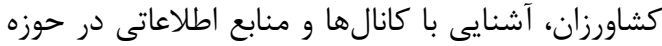

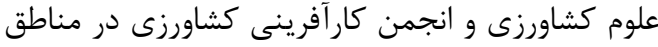

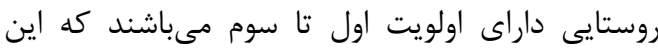

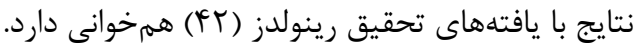

با بررسى انجام شده به لحاظ نظرى اين نتيجه به دست

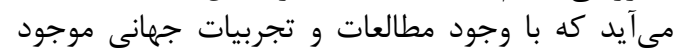

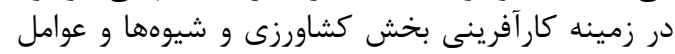

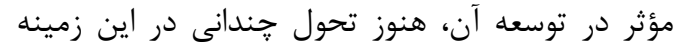

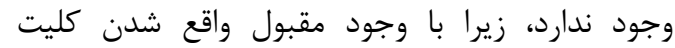

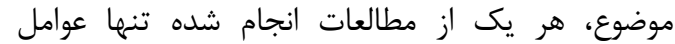

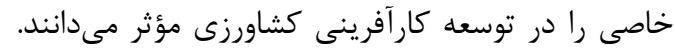

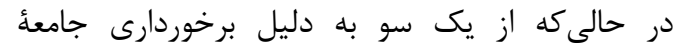
روستايى از منابع طبيعى و انسانى غنى و واز از سوى دئ ديكر

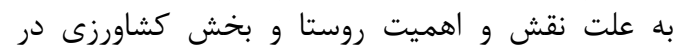

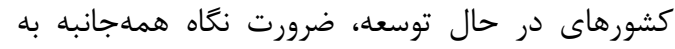

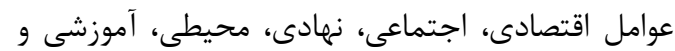

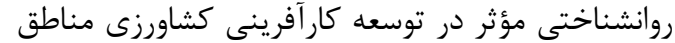

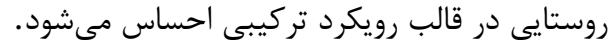

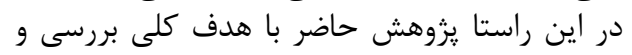

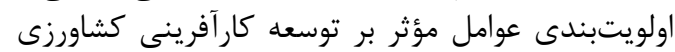

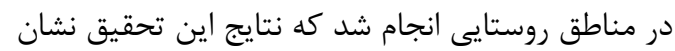

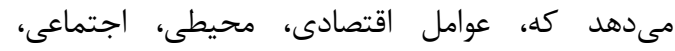
روانشناختى و آموزشى بر توسعه كار آفرينى كشاورزى إنى درى

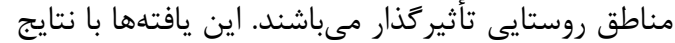

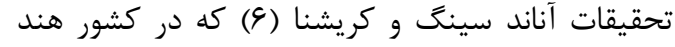

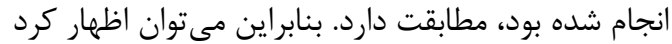

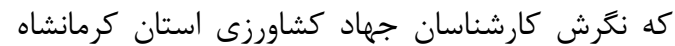
نيز مؤيد اين مسئله مىباشد كارندان 


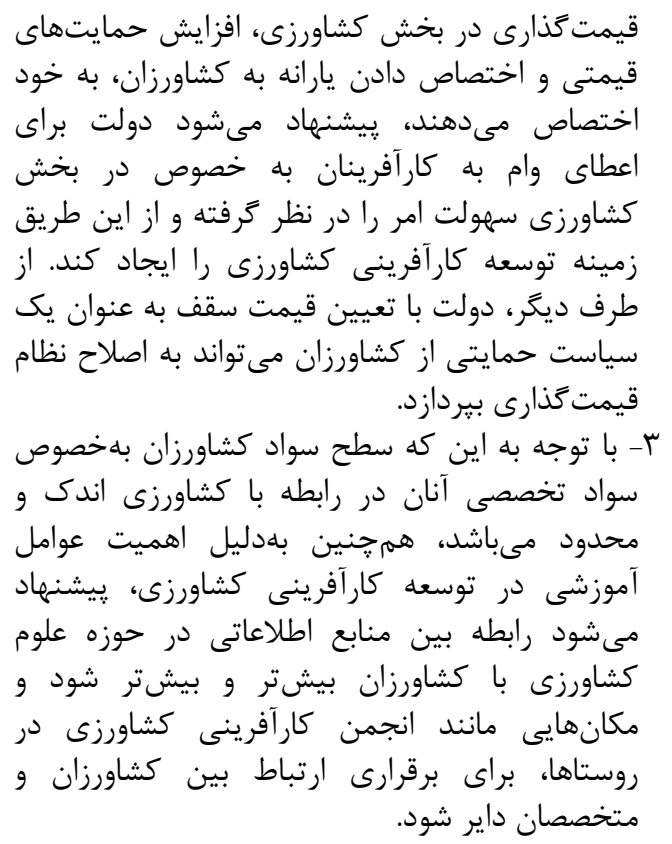

1. Abboud, M. 2012. The Role of Entrepreneurship in the Development of the Agricultural Sector. Taken from the http://roostaname.blogfa.com/9010.aspx, 1: 61-83.

2. Adelaja, S. 2007. Enabling Innovation in Michigan Agriculture, a Viable Agriculture Report. East Lansing: MSU Land Policy Institute, 11: 86-112.

3. Alison, M. 1990. Entrepreneurship: An International Perspective. Oxford: Linacre House, 2: 53-65.

4. Aghaei, M. 2009. Factors Affecting the Performance of Small-Scale Industry from the Perspective of Rural Development Experts. Journal of Rural Development, 11: 125-146 (In Persian).

5. Allen, J.C. and M. Alison. 2003. Examination of a Community Action Field Theory Model for Locality Based Entrepreneurship. Paper Presented at the Annual Rural Sociological Society Meeting, Montreal, Canada. 12: 32-55.

6. Anand Singh, K. and K.V.S.M. Krishna. 1994. Agricultural Entrepreneurship: the Concept and Evidence. Journal of Entrepreneurship, 3: 11_36.

7. Anbari, M. 2009. Analysis of the Problems and Shortcomings of Modern Research in the Sociology of Rural Development. Rural and Development Magazine, 6: 1-33 (In Persian).

8. APO. 2003. Development of Agribusiness Enterprises (Edited by Robert Oliver), Report of the APO Seminar on Development of Agribusiness Enterprises. Asian Productivity Organization, Tokyo, 23: 14-47.

9. Babson Park, M.A. and S. Shane .1993. Cultural Influences on National Rates of Innovation. Journal of Business Venturing, 8: 59-73.

10. Bahrami, A. 2005. Rural Development Planning Process. Proceedings of the Congress of Rural Development, Challenges and Prospects. Management and Planning Education and Research Institute, Tehran, 6: 145-160 (In Persian).

11. Batmali, T. 1989. Agriculture-Based Institutions for Agricultural Development Activities in the Credit Co-Operatives, Supply and Marketing, 47: 222-228.

12. Carney, D. 1998. Changing Private and Public Roles in Agricultural Service Provision. London: ODI, Natural Resources Group, 7: 96-73.

13. Cade. 2006. Mission Statement, Operating Principles, Goals and Objectives. Center for Agricultural Development and Entrepreneurship Strategic Plan. Available on: www.cadefarms.org/pdf/CADEStrategicPlanIII. pdf, 3: 112-125.

14. Chambers Edward, J. and E. Shaw Stuart. 2004. A Primer on Western Canadian Entrepreneurship. Edmonton: University of Alberta. The Western Centre for Economic Research, 18: 31-43.

15. Dabson, B., J. Malkin, A. Matthews, K. Pate and S. Stickle. 2003. Mapping Rural Entrepreneurship. Washington, D. C: Corp. for Enterprise Development, 12: 44-72. 
16. Danaei Fard, H. and A.AS. Azar. 2011. The Development of the Institutional Model of Entrepreneurship in the Agricultural Sector was Sub-Greenhouse. Entrepreneurship Development Magazine, 3: 7-27 (In Persian).

17. Drakakis, D. and D. Smith. 1995. Third World Cities: Sustainable Urban Development. Urban Studies, 32: 659-678.

18. Eftekhari, A., M. Pourtaheri and H. Sajasi Ghidari. 2011. Evaluation Criteria for Successful Performance of Ordinary Farmers and Rural: A Case Study, Khodabande City Villages and the Study of Human Geography, 72: 1-16 (In Persian).

19. Eftekhari, A., H. Sajasi ghidari and H. Razavi. 2011. Strategies for development of agricultural entrepreneurship in Rural Areas: a Case Study of the City Khodabande Villages. Journal of Rural Development, 3: 1-29 (In Persian).

20. Eftekhari, A. and H. Sajasi ghidari. 2011. Rural Development with an Emphasis on Entrepreneurship: Definitions, Perspectives and Experiences, Tehran, Publisher Samt, 16: 42-72.

21. Eftekhri, A., M. Taherkhani and H. Sajasi Ghedari, 2010. Analysis of Factors Affecting the Development of Agricultural Entrepreneurship in Rural Areas: A Case Study of City Khodabande. Journal of Rural Development, 12: 43-72 (In Persian).

22. Escap. 1996. Showing the Way: Methodologies for Successful Rural Poverty Alleviation Projects. Bangkok: ESCAP, 3: 43-72.

23. Golmohammadi, F. 2003. Appropriate Technology Transfer in the Village. Journal of Jihad, 24: 24-97 (In Persian).

24. Heriot, K. and N. Campbell. 2002. A new approach to rural entrepreneurship: A case study of two rural electric cooperatives. Available on: http://usasbe.org/knowledge/proceedings/proceedings Docs/USASBE2005proceedings-Heriot\%2030.pdf, 2: 13-21.

25. Hosseini, S.M. and S.M. Soleymanpour. 2007. The Effects of the Strengthening of the Entrepreneurial Spirit in the Process of Agricultural Development. Journal of Jihad, 26: 250-265 (In Persian).

26. Heydar Sareban, V. 2013. Factors Affecting Farmers Foster Entrepreneurship in Rural Areas. Journal of Geography, 10: 263-278 (In Persian).

27. Kanniainen, V. and V. Timo. 2005. Entrepreneurship and Labor Market Institutions. Economic Modeling, 22: 828-847.

28. Karimi, S., M. Chizari, H.J.A. Biemans and M. Mulder. 2010. Entrepreneurship Education in Iranian Higher Education: The Current State and Challenges, European Journal of Scientific Research, 48: 3550 (In Persian).

29. Kreft, S.F., S. Russell and T. Sobel. 2005. Public Policy, Entrepreneurship and Economic Growth. Cato Journal, 25: 595-616.

30. Lundy, M., F. Carlos and M.V.G. Ostertag. 2006. A Territorial Based Approach to Agro-Enterprise Development. Rural Agro-Enterprise Development Project, CIAT, 18: 112-140.

31. Macke, D. 2001. Situation Analysis Entrepreneurship and Rural Texas. Draft Report on Rural Entrepreneurship Initiative. Lincoln (Nebraska): Center for Rural Entrepreneurship, 6: 31-56.

32. Maria, L. 2002. Enhancing Entrepreneurship in Rural Tourism for Sustainable Regional Development: The Case of Söderslätt Region. Sweden: The International Institute for Industrial Environmental Economics (IIIEE); International Miljö Institute, 3: 19-43.

33. Mashdaei, A. 2011. Concepts, Challenges, and Offers Strategic Review of Barriers to Entrepreneurship in Iran. Available at: http://ttmnews.blogfa.com/post. 256 pp (In Persian).

34. Moghimi, M. 2009. Encyclopedia of Entrepreneurship. Tehran. Publisher's hampa. 241 pp (In Persian).

35. Mohanty, S.K. 2006. Fundamentals of Entrepreneurship. Prentice Hall of India, New Delhi, 8: 67-55.

36. Molenhuis, J. 1996. Agri-entrepreneurship: Opportunities in Nova Scotia. Farm Business Management and Economics, 8: 7-42.

37. Petrin, D. 2003. Entrepreneurship as an Economic Force in Rural Development, the FAO Regional Office for Europe. Translator: Hamid Zarnegar, Jihad Magazine, 22: 68-75.

38. Poorrajab, P. 2011. The Pathology of Rural Entrepreneurship in Iran. The Monthly Government Agencies, 6: 2-35 (In Persian).

39. Pour Dariani, A. 2002. Entrepreneurship: Definitions, Theories and Models 4, Tehran, publishing company, $300 \mathrm{pp}$ (In Persian).

40. Rabiei Monfared, H., S. Abdullahi, A.R. Omani and A. Noori Vandi. 2011. To Use entrepreneurship in the Agricultural Sector with a View to Developing Countries. Entrepreneurship Conference in Iran 1404, 4: 78-89 (In Persian).

41. Razavi, S.M. 2008. Encyclopedia of Entrepreneurship. Tehran, Publishers Hampa. 136 pp. (In Persian).

42. Reynolds, P.D., M. Hay and S.M. Camp. 1999. Glibal entrepreneurship monitor. Kansas city, MO: Kauffman Center for Entrepreneurial Leadership, 1: 21-55.

43. Rezvani, M.R. and M. Najarzadeh. 2008. Analysis of the Villagers in the Fields of Entrepreneurship Development of rural Areas Case study: South Bran Village of City. Journal of Entrepreneurship Development, 2: 161-182 (In Persian). 
44. Sajasi Gheidari, H., M. Paloj, A. Eftekhari and T. Sadeghloo. 2012. Providing Strategies for Development of Agricultural Entrepreneurship in Rural Areas by Using Multivariate Analysis, SWOT and MCDM. Journal of Agricultural Economics and Development, 74: 149-180 (In Persian).

45. Scott, L. 2006. Creating Entrepreneurial Communities; Lessons from 10 Rural Demonstrations in North Carolina. Available on: http://www.ncruralcenter.org/pubs/comm-demo-report.pdf, 2: 28-39.

46. Sexton, D., R. Pricer and P. Nenide. 2000. Measuring Performance in High Growth Firms. Presented at the Babson-Kauffman conference, 6: 43-57.

47. Shane, S. and S. Venkataraman. 2000. The Promise of Entrepreneurship as a Field of Research. Academy of Management Review, 25: 217-226.

48. Sharifzadeh, A., M.R. Mahboobi and A. Arabioon. 2010. Explained the Components of Business Development and Agriculture in the Province. The Development of Entrepreneurship, 11: 85-112 (In Persian).

49. Shrader, R. and M. Simon. 1997. Corporate Versus Independent new Ventures: Resource, Strategy, and Performance Differences. Journal of Business Venturing, 12: 47-66.

50. Sohn, J.H.D. 1994. Social Knowledge as a Control System: A Proposition and Evidence from the Japanese FDI Behavior. Journal of International Business Studies, 25: 295-324.

51. State Planning Organization. 2006. The General Policies of Article 44 of the Constitution of the Islamic Republic of Iran, the Management and Planning Organization of Iran, Tehran, 1: 32-58.

52. Steensma, K., L. Marino, M. Weaver and P. Dickson. 2000. The Influence of National Culture in the Formation of Technology Alliances by Entrepreneurial Firms. Academy of Management Journal, 43: 951-973.

53. Taub, R.P. 2004. Doing Development in Arkansas. Fayetteville, AR: University of Arkansas Press: $134 \mathrm{pp}$.

54. Tayyebi. S.K. and R. Nasr Esfahani. 2009. Evaluation of the Impact of Entrepreneurship Education Courses on Factor Entrepreneurship. Proceedings of the National Conference of Cooperative entrepreneurs, 16: 76-84 (In Persian).

55. Teece. D.J., G. Pisano and A. Shuen. 1997. Dynamic Capabilities and Strategic Management. Strategic Management Journal, 18: 509-533.

56. Van Den Ban, A. 1999. Agricultural Development: Opportunities and Threats for Farmers and Implications for Extension Organizations. Journal of Agricultural Education and Extension, 6: 145156.

57. Yaghoubi, J. 2006. Recognized Entrepreneurs in Agriculture and Applied Scientific Methods. Journal of Agricultural and Cooperatives, 20: 202-203 (In Persian). 


\title{
Investigation and Prioritization of Expert's views of Agriculture Jihad Organization of Kermanshah on Factors Affecting the Development of Agricultural Entrepreneurship in Rural Areas
}

\author{
Zahra Yusefi $^{1}$, Nader Naderi ${ }^{2}$, Bijan Rezaei ${ }^{2}$ and Nematollah Shiri ${ }^{3}$
}

1- M.Sc. Student, Razi University of Kermanshah, (Corresponding author: zahra.yusefi71@ gmail.com)

2 and 3- Assistant Professor and Ph.D. Student, Razi University of Kermanshah

Received: March 13, 2016

Accepted: May 18, 2016

\begin{abstract}
The overall goal of this study was to investigate the factors affecting the development of agricultural entrepreneurship in rural areas. The study population included all experts of Agriculture Jihad Organization of Kermanshah Proviance $(\mathrm{N}=197)$ that 130 of them were selected using Cochran's formula. The main research tool Researcher made questionnaire which had been made by a group of experts and its validity and reliability had been coefficient using Spss according to Cronbach's alpha coefficient (91\%). The Data in two descriptive and inferential statistics. Inferential statistics used in this study were Friedman nonparametric test and the average rating the results of this study showed that among the factors affecting the development of agricultural entrepreneurship in rural areas there is a significant difference statistically; So that based on the view of respondents Environment Factors have the greate impact and Socid factors have the smallest impact on the development of agricultural entrepreneurship in rural areas. The other Factors affecting the development of agricultural entrepreneurship include psychological, education and economics. According to the priorities of environmental factors, making appropriate laws and incentives for agricultural entrepreneurial activities and removing barriers such as obtaining permits and commissioning stages of entrepreneurial business, expanding and improving the possibility of living in the rural villages and making the vast possibilities available to villagers can provide the context of development of agricultural entrepreneurship in rural areas.
\end{abstract}

Keywords: Agricultural Entrepreneurship, Agriculture Jihad Organization of Kermanshah Province, Rural Development 